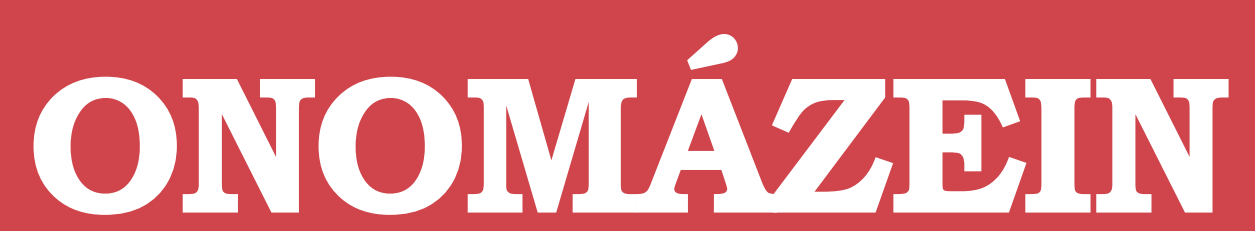

Revista de lingüística, filología y traducción
PONTIFICIA UNIVERSIDAD CATÓLICA DE CHILE FACULTAD DE LETRAS

\title{
El humor en los inicios del discurso lexicográfico en español ${ }^{1}$
}

Humor from the beginning of the lexicographic discourse in Spanish

\section{José Joaquín Martínez Egido}

Universidad de Alicante

España 


\section{Resumen}

El significado de las palabras y su uso en la lengua no están fijados en el tiempo. Este sería el caso de las voz humor, cuyo significado actual es nuevo en español tal y como se atestigua en los diccionarios. El discurso lexicográfico puede revelar datos suficientes sobre la historia de las palabras, de ahí que el objetivo de esta investigación sea conocer la concepción del humor que se desprenda en las obras de la primera etapa de la lexicografía en español, desde finales del siglo XV hasta comienzos del siglo XVIII. Con la obra de Covarrubias (1611) como punto de inflexión, se crea un corpus de diccionarios y se investiga en ellos cómo se trataba el tema del humor mediante la selección de voces relacionadas con él. Los resultados obtenidos son suficientemente claros tanto sobre la prudencia con que se concebía este tema, como sobre su uso pragmáticamente marcado.

Palabras clave: humor; discurso lexicográfico; léxico.

\section{Abstract}

Words meanings and their use in the language are not fixed in time. This is the case of the word humor, whose current meaning is new in Spanish, as it is attested in dictionaries. Lexicographic discourse can reveal enough data about the history of words. Therefore, the aim of this research is to find out the concept of humor that appears from the first papers in the Spanish lexicography, from the late fifteenth century to the early eighteenth century. Taking Covarrubias's dictionary (1611) as a turning point, a corpus of dictionaries has been compiled to do research on how the subject of humor was treated by the selection of voices related to it. The results are sufficiently clear in respect to the prudence with which this subject was conceived, as well as to its pragmatically marked use.

Keywords: humour; lexicographic discourse; vocabulary.

1 Este trabajo se enmarca en los Proyectos de Investigación: FFI2015-64540-C2-1-P "Género, humore identidad: desarrollo, consolidación y aplicabilidad de mecanismos lingüísticos en español” (201619) y Proyecto PROMETEO/2016/052 "Humor de género: Observatorio de la identidad de mujeres y hombres a través del humor" (2016-19) (Generalitat Valenciana). 


\section{Introducción}

El estudio descriptivo del léxico de una lengua, además de la representación del sistema lingüístico, incluye también aspectos pragmáticos que se reflejan, bien de forma directa o indirecta, en la construcción de los diccionarios (Rojas Gallardo, 2010) y que los deviene en importantes objetos culturales (Lara, 1997: 15). Por lo tanto, en esta investigación se parte de la idea de que el diccionario es el código por el que se rigen las palabras de una lengua. Estas comportan siempre un aporte ideológico, ya que su definición y sus ejemplos de uso siempre están conceptualizados y contextualizados. De esta forma, se convierten en indicadores claros de las relaciones comunicativas entre los miembros de una comunidad lingüística y, consecuentemente, del conjunto de las transformaciones sociales que les afectan (Voloshinov, 1992: 36).

Desde esta concepción, el análisis del discurso lexicográfico, caracterizado por ser siempre escrito y determinado por su organización técnica (Gutiérrez Cuadrado, 2011: 38-39), se muestra revelador para conocer el conjunto de pensamientos de sus autores, es decir, con él se puede conocer el ambiente que los circunda o, al menos, la interpretación de la realidad que cada lexicógrafo realiza, puesto que con su actividad redefinen el mundo al fijar un código con unos significados concretos (Forgas Berdet, 2007: 1). Ahora bien, la comprensión de lo integrado en un diccionario siempre entraña cierta dificultad. La representación del mundo mediante palabras siempre conlleva aspectos que deben ser interpretados lingüística y pragmáticamente para comprender la carga ideológica que contengan (Forgas Berdet, 1996; Rodríguez Barcia, 2012). En ese acto de comprensión e interpretación del contenido de un diccionario, habría siempre que atender, en primer lugar, a los contextos, parámetros culturales y sociales, de su producción y de su recepción que, por el devenir temporal, no siempre coincidirán; así como también, en segundo lugar, al propio producto lexicográfico, por ejemplo, los diccionarios destinados a hablantes nativos o los dirigidos a extranjeros.

El humor es uno de esos aspectos que reúne constantemente el componente lingüístico con un imprescindible componente pragmático (Santamaría Pérez, 2011; Herrero, 2014). Aunque su estudio se ha realizado desde diferentes ámbitos sociales² y desde diferentes perspectivas conceptuales y metodológicas³, el análisis del humor verbal tiene un desarrollo reciente. Desde cualquiera de esos ámbitos se intenta definir qué es el humor, así como también cuáles

2 Una exposición de ellos desde una perspectiva diacrónica puede encontrarse en Attardo, 1994.

3 Entre ellas, destacan la Lingüística Cognitiva, que basa sus aportaciones en el concepto de espacio mental (Brône, y otros, 2006); la Teoría de la Relevancia, que explica el humor como la resolución de una incongruencia producida por el emisor (Yus, 2016), y la Teoría General del Humor Verbal, que estudia el hecho humorístico como un mensaje lingüístico y pragmático (Attardo y Ruskin, 1991; Ruiz Gurillo, 2012). 
son los procedimientos lingüísticos, pragmáticos y metapragmáticos que lo hacen posible. En este trabajo, desde una clara perspectiva abarcadora, se concibe el humor como una manera de presentar la realidad mediante el uso de un componente aparentemente ilógico que, en su interpretación, conlleva un resultado cómico (Martínez Egido, 2016).

Ahora bien, esta concepción y su uso como herramienta de manifestación de lo ideológico pueden variar según el tipo de discurso en el que se utilicen y según la época en la que se empleen. Así, puede afirmarse que el componente cultural de una sociedad se caracteriza por la amalgama de los diferentes elementos que la integran y la definen, en este caso la centrada en el siglo XVII. Cada uno de ellos está presente, en mayor o menor medida, en lo que se considera el prototipo de persona ideal, modelo de conducta o comportamiento de la época. Uno de esos elementos, como se ha apuntado, es el humor verbal, tanto en lo concerniente a su conceptualización, como en lo referente a sus diversas manifestaciones sociales. En ellas cabe distinguir su aparición tanto en los discursos concebidos como humorísticos, por ejemplo, el que configura el personaje del gracioso en las comedias de Lope de Vega, como en los que no lo son, pero que pueden integrar el humor como un elemento más en su configuración.

A este respecto, existe el testimonio de Baltasar Gracián, filósofo español del siglo XVII, que puede actuar como referente sólido. Este autor, al mostrar las cualidades que deben regir en la vida de todo hombre de bien, quería conseguir que sus obras fueran una brújula para la excelencia (1996 [1637]: al lector). Uno de los aspectos que aborda es la presencia del humor en la vida diaria, concretamente en el realce o capítulo IX de su obra El Discreto (1646: 83-87), titulado "No estar siempre de broma. Sátira”.

En estas páginas su posición es muy clara frente al uso del humor verbal en la cotidianeidad, es decir, en los discursos habituales en los entornos laborales y personales, por lo tanto, no humorísticos en sí mismos. Gracián no duda en calificar a quienes lo usan en su día a día con aseveraciones personales tan nocivas como las siguientes:

No son hombres de veras; Consideran inferiores a los demás, Mentirosos, No hablan con juicio, pero porque no lo usan, no porque no lo tengan; Livianos; Monstruos aborrecibles de quienes todos huyen; Murmuradores cara a cara; Imprudentes; Afectados; poseen El ingenio siniestro; o son Siniestros de ingenio; y, por último, Mueren como grajos. Gracián, El Discreto (1996 [1646]: 83-87).

Ante esta negatividad, solo se constatan en sus escritos dos observaciones positivas: una relativa al propio carácter del emisor, el que tengan fama de ingeniosos, y la otra, relacionada con la finalidad de sus mensajes en el receptor, el que sean gratos al vulgo. Por otra parte, establece una diferencia en los productores de humor, ya que distingue al burlón del donoso al atribuirle a este que Vale mucho una gracia en su ocasión. Por tanto, puede deducirse de esa observación que la condena que presenta no es hacia el humor como posible elemento discursivo, sino hacia quienes lo usan de forma desaforada o, sobre todo, hacia quienes lo lle- 
van a la práctica según en qué situación comunicativa. Indudablemente, puede interpretarse que en sus palabras se halla una concepción pragmática de la valía y eficacia del humor en los discursos cotidianos, tal y como puede verse reflejada en la siguiente cita:

La prudencia es muy seria y la gravedad concita veneración; entre dos extremos es más seguro el carácter majestuoso. Quien siempre está de burlas nunca es hombre de veras, y algunos siempre lo están. [...] Las burlas deben tener su momento, y las veras todos los demás. [...] Hay que distinguir los tiempos y, mucho más, las personas. Gracián, El Discreto (1996 [1646]: 83-87).

Ante lo expuesto hasta ahora en este estudio, pude afirmarse que se parte de la hipótesis de que el discurso lexicográfico, en esta época concreta, puede reflejar tanto esa concepción de comedimiento ante el hecho humorístico como la consideración de su efectividad comunicativa en determinados contextos. Consecuentemente, el objetivo final de este trabajo es determinar cuál es la concepción del humor que se desprende del discurso lexicográfico desde finales del siglo XV hasta la publicación del Diccionario de autoridades (en adelante Autoridades) de la Real Academia Española (1726-1739), es decir, en la primera etapa de la lexicografía en español, pero incidiendo en el siglo XVII como piedra lexicográfica angular, o punto de inflexión, de este momento histórico. De esta forma, se podrá comprender cómo el humor fue codificado por los lexicógrafos y cuál fue la consideración sociocultural en la que este elemento se encontraba en sus propios discursos lexicográficos. Además, también puede empezarse a documentar de una forma fehaciente la historia del concepto del humor verbal en la lexicografía del español.

La metodología utilizada para la consecución de esos propósitos ha consistido, en primer lugar, en la configuración de un corpus de diccionarios objeto de observación. Estos se han seleccionado atendiendo principalmente a la cronología de las obras, es decir, a los inicios de la lexicografía del español: se comienza con el diccionario de español y latín de Nebrija (¿1495?), para continuar con el de español y árabe de Alcalá (1505), los de español y francés de Las Casas (1570), Palet (1604) y de Oudin (1607), los de español e inglés de Percyvall (1591) y de Minsheu (1599 [1617]), el monoligüe de Covarrubias (1611), el trilingüe, español, francés e italiano de Vittori (1609), el de español e italiano de Franciosini (1620) y, como contrapunto a todos ellos, dado su carácter académico y el momento de su publicación, Autoridades (1726-1739) (Azorín Fernández, 2002; Nieto Jiménez y Alvar Ezquerra, 2007; Martínez Egido, 2010).

En segundo lugar, se ha constatado en ellos la presencia de unidades léxicas que puedan servir para expresar significados dentro del campo del humor. Para ello, se ha tomado como base el Tesoro de Covarrubias (1611), del que se han extraído dichas unidades, siguiendo el esquema que supone el hecho comunicativo de la construcción del humor verbal (Attardo y Rusquin, 1991; Ruiz Gurillo, 2012), es decir, por una parte, quiénes son los productores o hacedores del humor, negativos y positivos, así como las cualidades de ambos, y, por otra parte, cuáles son los productos de dicho humor. 


\section{Análisis y resultados}

Dada la época de los inicios lexicográficos del español en la que se enmarca este estudio, el primer obstáculo encontrado ha sido el hecho de que los significados actuales de humor y humorismo no fueron constatados por los lexicógrafos en las obras estudiadas, puesto que, al parecer, no debían existir en el código lingüístico del español de la época. En ellas, solo se ha hallado la acepción referida al componente físico del humor, es decir, la recogida en el DRAE (2014) como acepción 6: "Cada uno de los líquidos de un organismo vivo". Este significado se corresponde con el aportado por Corominas y Pascual (1980-1991), quienes proponen una etimología sencilla para ese significante: "del latín ūmorūmoris, líquido, humores del cuerpo humano".

En la Edad Media se produjo una extensión del significado de la palabra humor, designando al genio o condición de alguien 4 , puesto que se asociaba el hecho de que los jugos o fluidos vitales influían en el genio de las personas. Como consecuencia de este significado, se desarrollarían los conceptos de 'buen humor' y 'mal humor', es decir, alguien podría tener uno u otro, siendo significativo el que fuera un sujeto quien los poseyera. Ahora bien, en ninguna de las obras consultadas se hace alusión a este doble significado, ya que en algunas ni tan siquiera se registra, como en el caso del Tesoro de Covarrubias. En los diccionarios en los que aparece, los lexicógrafos se limitan a ofrecer el equivalente en las lenguas de salida, al parecer, por las apreciaciones encontradas, siempre referidas al componente físico ya registrado: Las Casas (1570): Vmor, Humore; Palet (1604): Humore, Liqueur; Oudin (1607): Humeur, Liqueur, Moisteur; Vittori (1609): Humeur, Humore; Rosal (1611): de humore latino; Minsheu (1617 [1599]): Humor, Humour; Franciosini (1620): humore.

Será en Autoridades (1734) donde se glose lexicográficamente esa segunda acepción que se ha apuntado: "Se toma también por genio, índole, condición ò natural: especialmente quando se da a entender con alguna demostración exterior. [...]"; junto con la colocación Hombre de humor para designar a aquel que tiene "el genio jovial, festivo y agudo". Puede interpretarse, tanto de la designación general como de la aplicación particular, que la Academia ofrece una consideración positiva del humor, apoyada también en la inclusión del sustantivo humorada como "chiste gracioso, o hecho que se celebra, por el contento que da a los que lo ven y oyen".

Algo similar sucede con la voz humorismo, puesto que no aparece registrada en los diccionarios hasta el siglo XIX (Domínguez, 1853 [1846-1847]; Ulloa, 1855; Salvá, 1879 [1863], y Zerolo, 1895). En ellos, su significado siempre se refiere a la doctrina médica tradicional basada en los

4 Anónimo (1418 [1381]) en Real Academia Española: Banco de datos (CORDE) [en línea]. Corpus diacrónico del español [http://www.rae.es, 22/11/2016]. 
humores del cuerpo humano. Es a principios del siglo XX, concretamente en el diccionario de Toro y Gómez (1901), donde se glosa por primera vez como sinónimo de humorada (m. pr. Sant. Humorada. No hallaba chiste en sus humorismos [...]). Posteriormente, en la edición de 1914 del DRAE, aparece por primera vez una acepción referida a algo cercano al significado actual: "Estilo literario en que se hermanan la gracia con la ironía y lo alegre con lo triste". No obstante, ese significado sigue alejado del discurso propio de la vida cotidiana al circunscribirse al ámbito de la creación literaria. Lo mismo sucede con la inclusión en esa misma edición de la palabra humorista, ya que en su primera acepción se define como: "Dícese del autor en cuyos escritos predomina el humorismo".

No será hasta la edición de 1970 que su significado se extienda al español estándar con la acepción primera de "Ironía en la expresión”. No obstante, la caracterización de humorismo como una forma o herramienta de afrontar la realidad, tal y como se definía al principio de este trabajo, no aparecerá en el diccionario académico hasta la edición de 1984:

Humorismo. (De humor). m. Manera de enjuiciar, afrontar y comentar las situaciones con cierto distanciamiento ingenioso, burlón y, aunque sea en apariencia, ligero. Linda a veces con la comicidad, la mordacidad y la ironía, sin que se confunda con ellas; y puede manifestarse en la conversación, en la literatura y en todas las formas de comunicación y de expresión // 2. [...].

Esta definición es más extensa y explicativa que la propuesta en la última edición (2014) del diccionario académico, aunque ambas comparten la esencia del significado de esta unidad léxica en su primera acepción. Ahora bien, es reseñable que su significado se amplíe y se incluya una segunda acepción en la que se constata la profesionalidad de esta actividad:

Humorismo. (De humor e-ismo). 1. m. Modo de presentar, enjuiciar o comentar la realidad, resaltando el lado cómico, risueño o ridículo de las cosas. 2. m. Actividad profesional que busca la diversión del público mediante chistes, imitaciones, parodias u otros medios. 3. [...].

Con lo expuesto hasta este momento, puede afirmarse que, en su devenir diacrónico, el discurso lexicográfico analizado presenta tres significados o acepciones del humor: dos de ellos son expresivos o pasivos, y uno, perlocutivo o activo. Esto es, el humor se posee en cuanto a "líquido" y en cuanto a "genio", pero transciende del sujeto para entretener y agradar a un receptor concreto. Precisamente, es este significado perlocutivo el que es el objeto de nuestro estudio.

\subsection{El humor en los primeros diccionarios del español}

Al no poder rastrear este concepto perlocutivo mediante los significantes actuales que lo designan, ha de buscarse otros que pudieran contener ese significado en los diccionarios 
del corpus. Por otra parte, para este propósito, tampoco son factibles voces aparentemente útiles, como comedia o cómico (este último solo registrado por Minsheu, 1617 (1599); Covarrubias, 1611 y Autoridades, 1729), puesto que en todas las obras consultadas se alude bien al género teatral, bien a los participantes en el teatro, pero sin ninguna referencia a la posibilidad de humor y, en cualquier caso, siempre circunscritos al ámbito especializado de la representación teatral.

Para sistematizar esta tarea, siguiendo con lo dicho anteriormente, se ha realizado una doble división en la búsqueda y en el análisis de voces que puedan ser válidas para el objetivo de este estudio: en principio, vocablos que denominen a los agentes o hacedores de humor, tanto los considerados de forma negativa como de forma positiva; y, a continuación, términos que se refieran a los productos concretos del humor.

\subsubsection{Hacedores de humor}

En los diccionarios se incluyen vocablos que designan a personas que, bien de forma cotidiana, bien de forma profesional, realizan humor como un acto perlocutivo para mover a la risa a aquellos que los ven o escuchan con diversas finalidades. Según lo consignado en las obras lexicográficas, pueden distinguirse dos tipos de personas: los calificados negativamente y los considerados de forma positiva.

\subsubsection{Los negativos: El bufón, el chocarrero y el truhan}

En este primer grupo, los negativos, se encuentran el bufón, el chocarrero y el truhan. Así, respecto al primero, el bufón, como se verá más adelante, es el que menos presencia lexicográfica tiene, ya que solo aparece en cinco diccionarios con las siguientes glosas:

Oudin, 1607: Voyez Truhan.

Vittori, 1609: Truhan, Bouffon, buffone, bagatelero.

Covarrubias, 1611: Es palabra toscana, y significa el truhan, el chocarrero, el morrión, o bobo. [...] echando de su boca veneno de malicias y desvergüenzas, con que entretienen a los necios e indiscretos.

Minsheu, 1617 (1599): Boffonie, Vid. Truhan, chocarrero.

Autoridades, 1726: El truhan, juglar o gracioso, que con sus palabras, acciones y chocarrerías tiene por oficio el hacer reír: y se llama así porque entre otras muchas cosas e indecencias que sufre esta bajísima suerte de gente, es una [...].

En las microestructuras de las obras que definen este vocablo, se constata ese sentido negativo al que antes se hacía referencia y que plasmaba Gracián en su obra. Covarrubias le otorga 
descrédito a lo que dicen, descalificando a su público, y, por su parte, Autoridades lo clasifica en la escala social más baja. El resto de diccionarios ofrece equivalentes en las lenguas de salida, sin aportar tampoco ningún matiz positivo en ellas.

Caso similar es el de la voz chocarrero, pues también se observa en las redacciones de los artículos lexicográficos de las obras que lo glosan esa misma concepción no positiva:

Las Casas, 1570: Barattiere, barro, ciancione.

Percivall, 1591: a iester, giber, Mimus.

Palet, 1604: Bouffon, basteleur.

Oudin, 1607: Un benest, un badin, un babillard, un bauard, un bouffon, un causeur, un sot, un iaseur. Vittori, 1609: un benest, un badin, un babillard, un bauard, un bouffon, un causeur, un sot, un iaseur, charlatan, un pazzo, un ciarlone, un buffone, un zarlatano.

Rosal, 1611: del lat. Jocare, que significa burlar.

Covarrubias, 1611: El hombre gracioso y truhan [...] porque es hombre de burlas, y con quien todos se burlan; y también se burla él de todos, porque con aquella vida tienen libertad y comen y beben y juegan; y a veces medran más con los señores que los hombres honrados y virtuosos y personas de letras. Dicen que los palacios de los príncipes no pueden pasar sin estos.

Minsheu, 1617 (1599): L. Mimus, parasitus. [...].

Franciosini, 1620: burlone, chiacchierone, buffone.

Autoridades, 1729: El bufon, truhán y placentero, que siempre habla de burlas, para hacer reír a otros, sin tener otro empleo o ejercicio [...].

Esta palabra es recogida por diez obras del corpus establecido, sin que tampoco se observe ningún rasgo de positividad, aunque Covarrubias parece indicar que su suerte es buena, e incluso mejor que la de los hombres de bien, por lo que parece sugerir que ellos, los chocarreros, no lo son.

Y, por último, estaría la voz truhan, mencionada como posible sinónimo en las dos palabras anteriores y que es recogida en doce de los diccionarios, siendo, por tanto, la más presente en los diccionarios de las tres:

Nebrija, 1495: Truhan que mueve risa. Scurra.e.; Truan representador, bistrio.onis.

Alcalá, 1505, [4 entradas]: Truhan por comer; Truhan; Truhan que mueve a risa; Truhan representador.

Las Casas, 1570: Buffone.

Percival, 1591: a tester, scurra.

Palet,1604: basteleur, boufon, escornifleur.

Oudin,1607: bouffon, plaisant, basteleur, escornifleur, chercheur la repeuen franche, truand.

Vittori, 1609: bufon, truhan, bouffon, buffone, bagatelero.

Rosal, 1611: Del griego Truphá, que es el pasatiempo, burla, o juego. Y Truphás, tomar gusto y burlar de aquella manera, de donde el italiano llama Trupha a la cosa de burla y no de veras.

Covarrubias, 1611: El chocarrero burlón, hombre sin vergüenza, sin honra y sin respeto; ese tal, con 
las sobredichas calidades, es admitido en los palacios de los reyes y en las casas de los grandes señores, y tiene licencia de decir lo que se le antojare, aunque es verdad que todas sus libertades las viene a pagar con que le maltratan de cien mil maneras y todo lo sufre por su gula y avaricia, que come muy buenos bocados y cuando le parece se retira con mucha hacienda.

Minsheu, 1617 (1599): vid. Chocarero.L. Scurra [...].

Franciosini, 1620: buffone.

Autoridades, 1739: El que con acciones, y palabras placenteras, y burlescas, entiende en divertir, y causar risa a los circunstantes. [...].

Puede comprobarse tras este listado que, de nuevo, se contrapone la negatividad de Covarrubias en sus calificativos y en sus descripciones a la aparente buena consideración de Autoridades, que solo se limita a explicar su trabajo, consistente en hacer reír, por lo tanto, en hacer humor.

Por otra parte, es importante señalar que estos tres vocablos aparecen como sinónimos en las referencias internas que realizan los lexicógrafos para ofrecer sus equivalencias en las lenguas de salida. De ahí que pueda pensarse que las tres palabras en determinados contextos lingüísticos fueran sinónimas y que, todas ellas, fueran perdiendo su carga de negatividad con el paso de los años, tal y como demuestra el diccionario académico frente al de Covarrubias.

\subsubsection{Lo positivo: el gracioso y sus cualidades}

Frente a este sentido negativo del hacedor de humor, se encuentran también tres voces que encierran un sentido positivo hacia quien produce humor o hacia el propio acto de la producción, como son el gracioso y sus cualidades donaire y graciosidad.

La voz gracioso aparece en once de los diccionarios, siempre connotada de positividad:

Nebrija, 1495: gracia en hablar [...]. Gracia en esta manera: lepidus-a-um.

Alcalá, 1505: gracia en hablar [...]. Gracia en esta manera.

Las Casas, 1570: Auenente, faceto, gratioso, leggiadro.

Percival, 1591: gratious, pleasant, comely, thakfull, Lepidus, decorus, gratus.

Palet, 1604: Plaisant, gracieux.

Oudin, 1607: gracieux, agreable, affable, paisant, recognoissant.

Vittori, 1609: gracieux, agreable, affable, paisant, recognoissant, gratioso, gentile, affabile, amoreuole, piaceuole. La comida Graciosa: la repeue franche, la nuritura franca.

Minsheu, 1617 (1599): L. gratus, gratiosus [...].

Cavarrubias, 1611: Gracioso, el que tiene buen donaire y da contento el mirarle. [...] Gracioso, el que dice gracias. Agraciado, el que tiene gracia. [...].

Franciosini, 1620: grazioso, piaceuole, che ha garbo, e grazia. 
Autoridades, 1734, (7 acepciones en 7 entradas): - Adj. Hermoso, primoroso, perfecto, y que deleita y da gusto a quien lo ve. [...] // - Vale también chistoso, agudo, lleno de donaire y gracia. [...] // - Por antífrasis significa despropositado, fuera de camino. [...] // - Usado como sustantivo, significa el que en las Comedias y Autos tiene el papel festivo y chistoso, con que divierte y entretiene. [...] // -Más vale caer en gracia, que ser gracioso. Frase con que se significa, que valen poco las gracias personales, si la persona no es acepta a la voluntad. [...].

La gracia en hablar es la característica presente en todo el desarrollo lexicográfico, desde Nebrija hasta Autoridades, unida al decir gracias en Covarrubias. En este sentido, en todos los equivalentes que se ofrecen en otras lenguas, siempre se enfatiza el valor positivo del que es gracioso, ya alejado de las consideraciones de las tres voces anteriores cargadas de negatividad. Por otra parte, la reminiscencia de lo negativo del hacer humor o reír se constata en la unidad fraseológica que recoge el diccionario académico y que ha llegado a nuestros días, pues no es lo mismo ser gracioso que caer en gracia, de tal forma que el hecho de decir gracias como característica personal no se considera un buen atributo.

Por último, en esta voz habría que reseñar que es en Autoridades donde aparece gracioso por primera vez con valor sustantivo al atribuirlo a un tipo de personajes de las comedias, cuyo objetivo es el hacer humor para divertir al público del teatro.

Siguiendo con las tres voces propuestas, el gracioso tiene donaire, aunque esta palabra solo es constatada por cuatro lexicógrafos:

Nebrija, 1495: facetie-arum; fales-falium; festivitas-atis; comitas-atis.

Covarrubias, 1611: Vale gracia y buen parecer en lo que se dice, o haze; porque aire es lo mismo que grazia y espíritu, promptitud, viveza; decir donaires, decir gracias; pero si son perjudiciales, acarrean algunas veces desgracias; por donde tuvo origen el dicho común, Andaos a decir gracias: de uno que por mostrarse gracioso, dijo en lugar de gracia un lastima, y lastimaronle con darle una cuchillada por la cara. [...].

Minsheu, 1617 (1599): [...] a witty saying

Autoridades, 1732: Gracia y agrado en lo que se habla [...] // [...] Se toma asimismo por el chiste y gracia que se dice para atraer las voluntades de los que escuchan [...] // Andaos a decir donaires: Frase que se da a entender que no a todos les sale bien el decir chistes, pues algunos se ofenden al oírlos [...].

Nuevamente, el significado se relaciona de forma directa con lo que se dice con gracia o humor, tanto en Covarrubias, como en la traducción al inglés de Minsheu, un dicho ingenioso, como en Autoridades. En todos ellos el concepto es positivo y su posesión es un buen rasgo para su poseedor. Es de notar, mediante la inclusión de la unidad fraseológica Andaos a decir gracias, o su variante andaos a decir donaires, como es importante el momento y el saber decir esos dichos o esas gracias. El componente pragmático siempre está presente, tal y como apuntara Gracián, en la valoración del acto de hacer humor. 
La segunda cualidad positiva, que cerraría este apartado, sería la graciosidad, en la que, al igual que en donaire, es importante la discreción en lo que se dice. Ahora bien, si donaire se aplica a quien produce el humor, este nuevo concepto incide directamente en el mismo acto de producción del humor:

Minsheu, 1617 (1599): L. Urbanistas. A courtesie.

Autoridades, 1734: - f.f. Hermosura, perfección y excelencia de alguna cosa, que da gusto gusto y deleita a los que la ven u oyen. [...] // - Vale también chiste, donaire y gracia en el decir o hacer alguna cosa, de suerte que agrade o entretenga a los que lo ven o escuchan. [...].

Aparece en dos diccionarios del corpus y se observa la extensión de su significado, puesto que de un valor cortés pasa a significar algo que entretiene y que mueve a la risa. Por lo tanto, con la inclusión de esta palabra se constata de nuevo el cambio de actitud que opera en el receptor al sentirse agradecido, entretenido, ante una acción que comporta humor, emparentándose directamente con el matiz perlocutivo que posee en la actualidad.

\subsubsection{Productos del humor}

El acto de realizar humor conlleva la fabricación de un producto lingüístico que contenga todos los rasgos necesarios para que pueda ser considerado así. En este sentido, se han destacado cuatro voces que los representan, como son el chiste, la pulla, el mote y la gracia, recogidos, precisamente, en las microestructuras de las voces anteriores hasta aquí analizadas.

El chiste se constata en siete de los diccionarios, siempre con una consideración positiva y sin ningún matiz que lo pueda hacer reprobable:

Percival, 1591: jestes, loci ludis.

Palet, 1604: Sornettes, gaufferies, faceties.

Oudin, 1607: Friuoles, choses de neant, faceties, gaufferies.

Covarrubias, 1611: Vale donaire, y estos chistes le tienen cuando se dicen con mucha agudeza, y pocas palabras, y como a la oreja, del sonido chis, chis.

Rosal, 1611: Dicho gracioso, del latín serte, donosamente.

Franciosini, 1620: Gracia, gentileza, galantería, burla.

Autoridades, 1729: Dicho con donaire, gracia, agudeza, y prontitud, que da estimación a quien lo dice, y gusto al que le oye.[...].

Se insiste en la forma de hacerlos, con mucha agudeza; en la repercusión de mover a la gracia y, sobre todo, en el caso de ser placenteros para el que los escucha. Presentan, por tanto, definiciones y equivalencias en consonancia con el significado actual de la voz. 
Por el contrario, la segunda voz de este apartado, pulla, presenta dos acepciones próximas pero diferentes:

Nebrija, 1495: Dicterium.ii

Franciosini, 1620: Un detto grazioso, ma taluolta osceno, e dishonesto. Echar pullas. Dir detti per burlar uno, e per farlo rimaner ingannato, e beffaco dalla sua risposta, come s'uno decessi, halo tu visto? Colui necesariamente dira chi? L'altro soggiugne dicendo il piua, ch'e n nome finto.

Autoridades, 1737: - Dicho obsceno o sucio de que comúnmente usan los caminantes, cuando se encuentran unos a otros, u a los labradores que están cultivando los campos, especialmente en los tiempos de siega y vendimia. Y también se suelen usar entre las familias por burla de carnestolendas. [...] // - Se toma también por expresión aguda y picante, dicha con prontitud. [...].

Puede ser un dicho obsceno o gracioso, y así lo recogen las tres obras que la incluyen, pero, al parecer, la separación entre ambos valores es algo vaga. En este sentido, es interesante el hecho de que Franciosini recoja la unidad fraseológica echar pullas para testimoniar su uso. Con esto demuestra el valor de su diccionario y el de él como lexicógrafo al manejar diferentes fuentes, puesto que en la edición de sus Diálogos Apazibles (1626) hay ejemplos concretos de este uso5. Por otra parte, el resto de diccionarios estudiados no incluye este significado de pulla, ni tampoco en su variante ortográfica, puya. En todos ellos, tanto con una ortografía o con otra, incluyen esta voz, pero con el significado de rama, palo o varilla.

Siguiendo con el análisis de unidades léxicas de este apartado, estaría la voz mote, la cual, aunque presenta muchas acepciones diversas ${ }^{6}$, comparte significado con la palabra anterior:

Nebrija, 1495: - Mote o motete. Epigrama.atis. // - Mote lastimero. Dicterium.ii.

Alcalá, 1505: Mote o motete.

Las Casas, 1570: Detto, motto.

Percival, 1591: A saying, a quip, a nip, dicterium. Scomma.

Palet, 1604: Mot, deuise.

Oudin, 1607: Un mot, diction d'une deuise, un brocard, un lardon.

Vittori, 1609: Un mot, diction d'une deuise, un brocard, un lardon, gausserie, uno detto, o una sentencia di una diuisa, o una puntura da ridere.

Covarrubias, 1611: Vale tano como una sentencia dicha con gracia y pocas palabras. [...] Algunas veces significa dicho agudo y malicioso, que en latín llamamos directium [...].

Rosal, 1611: Es copia, nombre o dicho levantado o movido contra alguno [...].

5 "A. Pedro allà viene vn caminante echale vna pulla. // P. Olà hermano por donde van? // Caminante: A dò? // En casa de la puta, que os pario". A. Buena à fè, otra al compañero que queda atrás. // P. Señor es suyo el mulo? // Cam. Qual mulo? // A quèl que le basèis en el culo" (Franciosini, 1626: 88-89).

6 Todas las acepciones expuestas en los diccionarios estudiados están recogidas de alguna manera en la edición del DRAE, 2014. 
Minsheu, 1617 (1599): L. Emblema. A. a moto, [...].

Franciosini, 1620: -Motto, detto pungente. // -Motto. Sentenza breue e detta con grazia.

Autoridades, 1734: - f.m. Sentencia breve, que incluye algún secreto o misterio, que necesita explicación. [...] // - Se toma también por apodo, dicho con una voz o palabra. [...].

En este caso, es interesante la apreciación de ser un dicho sentencioso y breve y, en ocasiones, también malicioso, pero dicho siempre con gracia, como bien glosa Covarrubias. Este hecho demostraría, por tanto, las distintas formas de designar el concepto de humor en este momento histórico, pero siempre con la acepción de decir o hacer algo con gracia.

Es precisamente esta voz, gracia, la que cierra este subapartado de productos de humor. Es quizá la palabra que más ha sido utilizada por los lexicógrafos en la redacción de los artículos lexicográficos de sus diccionarios para definir los vocablos anteriores objetos de nuestro estudio, asociadas todas ellas al campo semántico del humor. Esta voz se constata en doce de los diccionarios del corpus establecido:

Nebrija, 1495: Gracia en hablar. Lepor.oris; lepiditas.atis.

Alcalá, 1505: Gracia en hablar.

Las Casas, 1570: Gracia o donayre. Facctia.

Percival, 1591: Grace, fauor, comlines, beautie, pleasantness, thanks, gratia, décor, lepos, gratiae.

Palet, 1604: Plaisir, gre, grace, mercy, pardon.

Oudin, 1607: Grace, beaute, ioliucte, bienseance, gre: remission, pardon, mercy.

Vittori, 1609: Grace, beaute, ioliucte, bienseance, gre: remission, pardon, mercy, beltade, o belleza, grato, \& perdono, rimessione. Decir gracias, dire desfaceties \& plaisanteries, dire delle fauole, o cose dilettose, \& piacevoli. Gracia o donaire [...].

Covarrubias, 1611: Gracia. [.. Alguna vez significa el beneficio que hacemos o el que recibimos [...] Tener gracia, tener donaire y agrado. [...] Decir gracias, chacotear agudamente, aunque si no se hace con discreción suelen costar muy caro; y así por aquel que le habían dado una cuchillada por donoso perjudicial, quedó el proverbio: "Andaos a decir gracias".

Rosal, 1611: Ora sea el donaire y hermosura, ora el agradecimiento, [...].

Minsheu, 1617 (1599): L. gratia. A. grace, favor [...].

Franciosini, 1620: Dono, o grazia gratis data.

Autoridades, 1734: [...] Vale asimismo chiste, facecia, dicho agudo discreto y de donaire.

En todos estos artículos lexicográficos, aunque se presentan diferentes acepciones, y se define con sinónimos ya glosados, como donaire, chiste, dicho agudo, chacotear, etc., se reitera el hecho de ser considerada la gracia siempre como algo bueno y positivo. Además, en todos los casos, se presenta el denominador común de que el tener gracia es el agradar al interlocutor en algo, consignándose de nuevo el carácter perlocutivo del humor. Y, asimismo, se insiste en la necesidad del comedimiento en su exposición, ya señalado por Covarrubias y por Autoridades, cuestión que se ve remarcada con el significado de la unidad fraseológica andaos a decir gracias ya incluida en la voz donaire. 


\section{Conclusiones}

El planteamiento teórico formulado ha resultado satisfactorio para confirmar la hipótesis de partida. El análisis del discurso lexicográfico realizado confirma la imagen ideológica que en la época estudiada se tenía sobre el concepto del humor: mucha prudencia ante el hecho humorístico. Ahora bien, se consideraba como un buen elemento pragmático para conseguir determinados fines, tal y como en cierta medida propugnaba Gracián.

Con la metodología utilizada, se ha logrado el objetivo planteado, ya que es posible afirmar que los diccionarios estudiados expresan un concepto del humor acorde con el sentir de la época, es decir, ese discurso lexicográfico ha mostrado una cuestión ideológica: el humor está presente en la vida cotidiana, pero debe emplearse con mucha prudencia en situaciones cotidianas: solo en aquellas ocasiones que así lo requieran y solo con las personas oportunas. Aunque el concepto de competencia pragmática sea reciente, se ha comprobado que estaba incluido en el discurso lexicográfico de la primera etapa de la lexicografía del español. En estas obras lexicográficas, el uso lingüístico fue un parámetro definitorio de las voces junto al baremo normativo.

Se ha podido demostrar cómo el significado de humor ha ido variando a lo largo de la historia del español. En un principio heredó del latín el significado ligado a lo físico del cuerpo humano y, posteriormente, se extendió al carácter o genio. Avanzado el tiempo, adquirió el valor de ser un modo de presentar la realidad, primero solo dentro de la literatura, pero, después, en cualquier ámbito de la vida cotidiana. Por tanto, pasó de ser un concepto pasivo, poseído por la persona, a ser un concepto activo y perlocutivo, al proyectarse hacia los demás y al conseguir una reacción en el receptor.

Salvadas las cuestiones formales propias de las voces estudiadas, el discurso lexicográfico se ha mostrado como un testimonio lingüístico esclarecedor de conceptos socioculturales, como en este caso el humor, ya que se ha expuesto cómo fue su codificación en los diccionarios y, de ahí, cuál fue su consideración como posible elemento lingüístico y pragmático.

A partir de los resultados obtenidos, debe continuarse con el estudio de nuevas voces, y de unidades fraseológicas, atendiendo a las características definitorias de cada diccionario (finalidades, receptores específicos, lenguas incluidas, etc.), que puedan ser susceptibles de ser usadas en el campo semántico del humor. De esta forma, se conocerán mejor los ámbitos comunicativos en los que se utilizaban y cuáles podrían ser los efectos perseguidos y conseguidos.

\section{Bibliografía citada}

AlcalÁ, Fray Pedro de, 1505: Vocabulista arábigo en letra castellana, Granada.

Anónimo, 1418 [1381]: Sevillana medicina de Juan de Aviñón, Sevilla: Juan de Burgos. 
Attardo, Salvatore, 1994: Linguistic Theories of Humor, Berlín: Mouton de Gruyter.

AtTARDo, Salvatore, y Víctor Ruskin, 1991: "Script theory revis(it)ed: Joke similarity and logical mechanisms", Humor 4 (3-4), 293-347.

Azorin Fernández, Dolores, 2002: Los diccionarios del español en su perspectiva histórica, Alicante: Publicaciones de la Universidad de Alicante.

Brône, Geert, Kurt Feyaerts y Tony Veale, 2006: "Introduction: Cognitive Linguistics approaches to humor", Humor 19-3, 203-228.

Corominas, Joan, y José Antonio Pascual (1980-1991): Diccionario crítico etimológico castellano e hispánico, Madrid: Gredos.

Covarrubias, Sebastián de, 1611: Tesoro de la Lengua Castellana o Española, Madrid: Luis Sánchez.

Dominguez, Ramón Joaquín, 1853 [1846-1847]: Diccionario nacional o Gran diccionario clásico de la lengua española (1846-1847), 2 vols., Madrid-París: Establecimiento de Mellado.

Forgas Berdet, Esther, 1996: "Lengua, sociedad y diccionario: La ideología” en Esther Forgas (coord.): Léxico y Diccionario, Tarragona: Universitat Rovira i Virgili, 71-90.

Forgas Berdet, Esther, 2007: “Diccionarios e ideología”, Interlingüística 17, 2-16.

Franciosini, Lorenzo, 1620: Vocabolario español-italiano e italiano-español, Roma: Rufineli y Manni.

Franciosini, Lorenzo, 1626: Dialogos apacibles coompuestos en castellano y traduzidos en toscano, Venetia: Giacomo Szarzina.

Gracián, Baltasar, 1996 [1637]: “El Héroe” en J. Ignacio Diez Fernández (ed.): El hombre en su perfección, Madrid: Ediciones Temas de Hoy.

Gracián, Baltasar, 1996 [1646]: “El Discreto” en J. Ignacio Diez Fernández (ed.): El hombre en su perfección, Madrid: Ediciones Temas de Hoy.

Gutiérrez Cuadrado, Juan, 2011: “Ideología y Lexicografía” en Félix San Vicente, Cecilio Garriga y Hugo Lombardinı (coords.): Ideolex. Estudios de Lexicografía e Ideología, Monza/Italia: Polimetrica Intarnational Scientific Publisher.

Herrero Ingelmo, José Luis, 2014: "Humor en los diccionarios: la marca festivo/humorístico en los compuestos de verbo más complemento directo" en María Bargalló Escriva y otros (eds.): "Llaneza": estudios dedicados al profesor Juan Gutiérrez Cuadrado, A Coruña: Universidade de A Coruña, Servicio de publicaciones, 305-317.

LARA, Luis Fernando, 1997: Teoría del diccionario monolingüe, México: El Colegio de México. 
LAS CASAS, Bartolomé de, 1570: Vocabulario de las dos lenguas toscana y castellana, Sevilla.

Martinez Egido, José Joaquín, 2010: La obra pedagógica del hispanista Lorenzo Franciosini, Monza-Milano: Polimetrica.

Martinez Egido, José Joaquín, 2016: "Humor y noticias económicas y financieras en la prensa española”, Lingüística española actual XXXVIII (1), 161-185.

Minsheu, John, 1617 [1599]: A dictionarie in spanish and english, London.

NebRIIA, Antonio de, ¿1495?: Vocabulario de romance en latín, Salamanca-Madrid: Facsímil de la Real Academia Española de la lengua.

Nieto Jiménez, Lidio, y Manuel Alvar Ezquerra, 2007: Nuevo Tesoro Lexicográfico del Español (s. XIV-1736), Madrid: Arco Libros.

Oudin, César, 1607: Tesoro de las lenguas francesa y española, París: Marc Orry.

Palet, Jean, 1604: Diccionario muy copioso de la lengua española y francesa, París: Mathieu Guillemot.

Percyvall, Richard, 1591: Bibliotheca Hispanica, London.

Real Academia Española, 1726-1739: Diccionario de autoridades, Madrid: Autor.

Real Academia Española, 2016, Nuevo tesoro lexicográfico [http://www.rae.es, fecha de consulta: 15 de noviembre de 2016].

Rodriguez Barcia, Susana, 2012: "El análisis ideológico del discurso lexicográfico: una propuesta metodológica aplicada a diccionarios monolingües del español”, Verba 39, 135-159.

Rojas Gallardo, Darío, 2010: "Estandarización lingüística y pragmática del diccionario: forma y función de los 'diccionarios de provincialismos' chilenos”, Boletín de Filología 45 (1), 209-233 [http://www.scielo.cl/scielo.php?script=sci_arttext\&pid=\$0718-93032010000100009, fecha de consulta: 15 de noviembre de 2016].

Rosal, Luis de, 1611: Diccionario etimológico, edición de E. Gómez Aguado (1992), Madrid: C.S.I.C.

Ruiz Gurillo, Leonor, 2012: La lingüística del humor en español, Madrid: Arco Libros.

Salva, Vicente, 1879 [1863]: Suplemento. Nuevo diccionario de la lengua castellana, París: Librería de Garnier Hermanos.

Santamaria Pérez, María Isabel, 2011: "Entre la pragmática y la Lexicografía: La marca 'humorístico' en los diccionarios monolingües de aprendizaje del español”, Revista de Lexicografía XVII, 179-208. 
Toro y Gómez, Miguel de, 1901: Nuevo diccionario enciclopédico ilustrado de la lengua castellana, París-Madrid: Librería Armand Colin - Hernando y Cía.

UlloA, Augusto, 1855: Biblioteca ilustrada de Gaspar y Roig. Diccionario enciclopédico de la lengua española, Madrid: Imprenta y Librería de Gaspar y Roig.

VITTORI, Girolamo, 1609: Tesoro de las tres lenguas francesa, española e italiana, Ginebra: Albert \& Pernet.

Voloshinov, Valentin Nikòlaievich, 1992: El marxismo y la filosofía del lenguaje, Madrid: Alianza Editorial.

Yus, Francisco, 2016: Humour and Relevance, Amsterdam/Philadelphia: John Benjamins Publising Company.

Zerolo, Elías, 1895: Diccionario enciclopédico de la lengua castellana, París: Garnier Hermanos. 